\title{
Design of High-Frequency ZVS Full-Bridge Power Converter for Photovoltaic Applications
}

\author{
Wasan Phetphimoon $^{1}$, Yuttana Kongjeen ${ }^{2}$, Krischonme Bhumkittipich ${ }^{1}$
}

\begin{abstract}
This paper presents the design of a high-frequency Zero Voltage Switching (ZVS) fullbridge converter with a phase-shifted driving signal for photovoltaic applications. According to the rapid development of power electronics technology, the smart power converter could provide high-power capacity with the high-frequency operation and achieve high energy delivery to the load. This power converter could also reduce the size of the transformer compared to the same power rating. The transformer has been developed using resonant technique and selecting the optimal switching frequency whereby the power converter could reduce switching loss and improve the system efficiency. The phase-shifted modulation switching technique has been selected to drive the power semiconductor switches of a full-bridge power converter based on the switching loss minimization method. The desired output voltage has been controlled using a closed-loop controller under a loop gain stability margin. The simulation results have showed that the output voltage could be controlled to the desired constant when the input voltage has changed from 370 VDC to 400 VDC. The output voltage of the power converter could be controlled at a constant of 24 VDC. Therefore, the proposed study has showed the effectiveness of the phase-shifted ZVS fullbridge power converter for photovoltaic applications such as the battery charging system. This power converter could operate at the desired voltage system and reduce the sizing of the power converter under high-performance efficiency. Copyright (C) 2021 The Authors.

Published by Praise Worthy Prize S.r.l. This article is open access published under the CC BY-NC-ND license (http://creativecommons.org/licenses/by-nc-nd/3.0/).
\end{abstract}

Keywords: Phase-Shifted Full-Bridge, Power Converter, Photovoltaics, Zero Voltage Switching, Switching Loss

\section{Nomenclature}

$L_{r} \quad$ Resonant inductance

$C_{T R} \quad$ Transformer winding capacitance

ZVS Zero Voltage Switching

$\delta t_{\max } \quad$ Deadtime maximum

$L_{f} \quad$ Output filter inductance

$I_{\text {Load }} \quad$ Load current

$C_{m o s} \quad$ Capacitance of the MOSFET

$D_{\text {eff }}$

$N_{P}$

$N_{S}$

$V_{P}$

$V_{S}$

$I_{P}$

$I_{S}$

$V_{\text {in }}$

$V_{\text {out }}$

$\mathrm{HF}$

$C_{o}$

$V_{D C}$

$p h_{\text {eff }}$

$B_{\max }$

$f_{s}$

$f_{r}$

\begin{abstract}
$\Delta V_{o} \quad$ Output voltage ripple
$V_{G S} \quad$ Gate to source voltage

$V_{D S} \quad$ Drain to source voltage
\end{abstract}

\section{Introduction}

Photovoltaic systems are renewable energy systems in which solar energy is transformed into electricity using semiconductor materials. The photovoltaic systems can replace electric power plants because of fossil fuel usage, energy availability, environmental pollution due to carbon dioxide emissions, and rapid fossil fuel consumption.

Integrating solar energy sources into existing energy infrastructure is derived by the general installation of distributed generation to increase power system stability.

The typical photovoltaic systems select the power electronic equipment such as power converter to convert output solar energy voltage to desired voltage [1]. Either in a balanced or in a unbalanced state, the system supplies electricity to the solar power plant with the required power and developed strategies. Therefore, the inverter can be used as a reactive power compensator [2] and a converter switching frequency. 


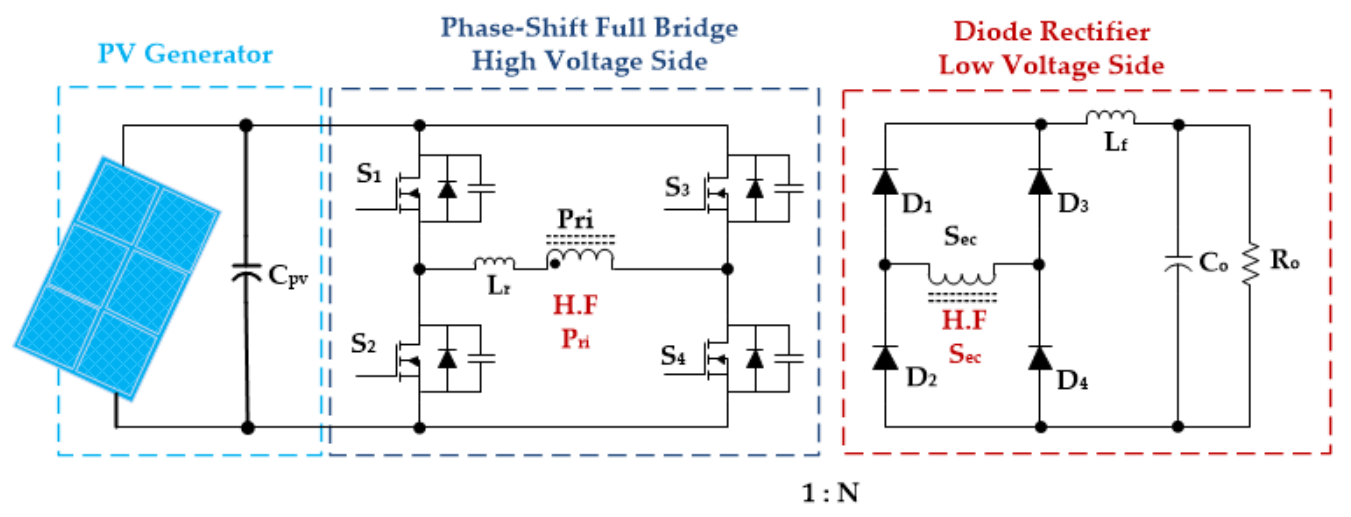

Fig. 1. The full-bridge power converter for photovoltaic systems

This relationship is valid for both stable and unstable systems [3], particularly in non-linear voltage regulation schemes using the integrated shift mode control method in order to drive the applied single-phase modulation technique [4]-[6]. This is a new pulse-wide modulation technique for controlling the output voltage and the voltage balancing of the dc-bus capacitors of multi-stage clamp-on converters. Voltage equalization is achieved by allowing each converter's pin voltage to switch between multiple levels during a single modulation period [7], [8].

The electrical power conversion is performed by power electronics principles, mainly the high switching frequency and the consequence of the switch's resulting power loss and electromagnetic interference [9].

Therefore, an important part of photovoltaic systems is a power converter that can draw the solar energy power to load level. The control indices of a photovoltaic system are desired value, system performance, and power switching loss, which have been considered in the proposed system [10]-[13]. Nowadays, the photovoltaic system design is centered on increasing the power capacity using modern power converter technology in order to improve the high-power ability of transformers and reduce the size of the transformer using highfrequency operation [14]. For the above design purpose, in this paper, a high-frequency Zero Voltage Switching (ZVS) power converter that could control the desired voltage rapidly and isolate the electrical ground system [15] has been chosen. A high-power ZVS power converter has selected the soft switching operations that could reduce the power switching loss of power converter during turn-on and turn-off of power switches.

The PWM technique with the phase-shifted operation has been selected to drive the resonant full-bridge power converter [16], [17].

Fig. 1 shows the proposed power converter circuit for photovoltaic application. The main power converter topology consists of the solar panel source, a full-bridge converter, a high-frequency transformer, a highfrequency rectifier circuit, and a desired load.

Therefore, this paper proposes the control for fullbridge power converters. It provides a path for power flow and a full load range for lightweight conditions without additional power circuits. The proposed mathematical models will express the principles and the advantages of the proposed control algorithm methods, including linear phase-shifted voltage and ZVS operation.

The rest of this paper is organized as follows. Section II presents the principal operation of the phase-shifted full-bridge power converter and expresses the mathematical model of the proposed power converter.

The mathematical model of a high-frequency transformer for designing the optimal transformer in this study is presented in Section III.

Section IV offers the design of the high-frequency power converter. The simulation results are shown in Section V. Finally, the discussion and the conclusion are given in Section VI.

\section{Phase-Shifted Full-Bridge Power Converter}

The phase-shifted full-bridge power converter is a full-bridge DC-DC power converter with three cascade parts for energy conversion. The first part is a DC to AC phase-shifted full-bridge converter connected to highfrequency transformers sides, the second part is an AC to $\mathrm{AC}$ high-frequency transformer, and the third part is an $\mathrm{AC}$ to DC high-frequency power rectifier.

There are four power-switching devices in the topology of the full-bridge phase-shifted power converter with ZVS operation [18]. The power switches are turned on and off complementarily with a $50 \%$ duty cycle.

Conversely, the opposite power switches are turned on and off with a different strategy.

The power switches shift the phase depending on the control driving signal. The inductor energy for achieving ZVS is calculated as (1):

$$
E=\frac{1}{2} L_{r} I_{2}^{2} \geq \frac{3}{4} C_{m o s} V_{i n}^{2}+\frac{1}{2} C_{T R} V_{i n}^{2}
$$

where $I_{2}$ is the current flowing through the primary side when $S_{2}$ is stopped, $V_{\text {in }}$ is the input voltage of the circuit, and $C_{o}$ is the capacity of the transformer coil.

The transformer factor of $4 / 3$ is the double power 
stored in a nonlinear drain. The capacity varies according to the square root of the input voltage [19]. The resonance among the values of $L_{r}, C_{m o s}$ and $C_{T R}$ lets the sinusoidal voltage pass the maximum capacity at onefourth of the resonant frequency range. The deadtime can be set between $S_{3}$ and $S_{4}$ by setting the value of $\delta t_{\max }$, in order to be sure that there is sufficient charging time and discharging time. The ZVS connecting time at the highest possible load can be determined by the following (2):

$$
\delta t_{\max }=\frac{T}{4}=\frac{\pi}{2} \sqrt{L_{r} C}
$$

where $C=C_{\text {mos }}+C_{o}$. The interval of zero switching conditions of $S_{3}$ and $S_{4}$ will vary with the load level of the converter.

The load current is low when closed and it may not be sufficient to activate for parallel protection signal for switching $S_{1}$ and $S_{2}$.

Thus, before $S_{1}$ is turned off, the main current reaches the maximum value and then $S_{1}$ is turned off. Hence, the available power charges the output capacity of $S_{1}$ and discharges the output capacity $S_{2}$. This inductive filter output is provided because the filter inductor does not rotate through the regulator until the second voltage is reduced to zero. The energy inductance of the filter is large compared to the energy stored in the switched capacitor. The current switching method implementation can be estimated by charging in the linear equation form with the constant current.

Therefore, the dead time required during turn-on and turn-off of $S_{1}$ and $S_{2}$ can be obtained in (3):

$$
\delta t_{1} I_{p}=4 C_{\text {mos }} V_{\text {in }}
$$

$4 C_{\text {mos }} V_{\text {in }}$ corresponds to the double charging stored in nonlinear output. The capacity of the power electronic switches device and $I_{p}$ are the maximum current in the inductive filter output.

The reflection of the main deadtime can be calculated as the lowest value selected to get the ZVS operation. If the current is reduced, the ZVS operation cannot be controlled. The ZVS occurrence, $S_{1}$ and $S_{2}$ operating range can be achieved even at a light load because $D_{1}$ and $D_{3}$ can be opened by the energy stored in the inductor. However, ZVS for $S_{2}$ and $S_{4}$ can only be used for load currents that are higher than the critical values as shown in (4):

$$
I_{C R I T}=\sqrt{\frac{2}{L_{r}}\left(\frac{4}{3} C_{m o s} V_{i n}^{2}+\frac{1}{2} C_{T R} V_{i n}^{2}\right)}
$$

The current can be calculated from the equation as shown in (5):

$$
I_{2}=\frac{N_{s}}{N_{p}}\left(I_{\text {load }}+\frac{\Delta I}{2}-\frac{V_{\text {out }}}{L_{r}+L_{m}}(1-D) \frac{T}{2}\right)
$$

Finally, the value of the ZVS can receive the load current, as shown in (6):

$$
I_{\text {load }} \geq \frac{N_{p}}{N_{s}} I_{C R I T}-\frac{\Delta I}{2}+\frac{V_{\text {out }}}{L_{r}+L_{f}}(1-D) \frac{T}{2}
$$

\section{II.1. Operation State of the High-Frequency Power Converter}

The power converter equivalent circuits can directly replace the full-bridge high-frequency power converter circuit, as shown in Fig. 2. The switch can be partitioned into two sets of state-based sub-circuits, switches, and shortcuts for the status of the switch: $0 \leq t \leq d T_{S}$, $d T_{S} \leq t \leq T_{S}$. The induced current and the capacitor voltage have been chosen as a state variable of output voltage [20]. In the $0 \leq t \leq d T_{S}$ period $S_{1}, S_{4}$ or $S_{2}, S_{3}$ or performing in Fig. 2 is the equivalent circuit of the highfrequency power converter, and its equation is shown in (7):

$$
\left\{\begin{array}{l}
L \frac{d i_{L}}{d t}=\frac{V_{g}}{n}-V_{C} \\
C \frac{d v_{C}}{d t}=i_{L}-\frac{v_{C}}{R}
\end{array}\right.
$$

In the $d T_{S} \leq t \leq T$ period $S_{1}, S_{4}$ or $S_{2}, S_{3}$ are turned off. Fig. 2 shows the equivalent circuit, and its equation is as expressed in (8):

$$
\left\{\begin{array}{l}
L \frac{d i_{L}}{d t}=-V_{C} \\
C \frac{d v_{C}}{d t}=i_{L}-\frac{v_{C}}{R}
\end{array}\right.
$$

Then, for equations (7) and (8), the average value is $(7) \times d+(8) \times(1-d)$, the duty cycle is the $d$ value in $(9)$ :

$$
\left\{\begin{array}{l}
L \frac{d i_{L}}{d t}=2 d\left(\frac{V_{g}}{n}-v_{C}\right)+2 d \frac{-v_{C}}{T_{S}} \\
C \frac{d v_{C}}{d t}=2 d\left(i_{L}-\frac{v_{C}}{R}\right)+2 d\left(i_{L}-\frac{v_{C}}{R}\right)
\end{array}\right.
$$

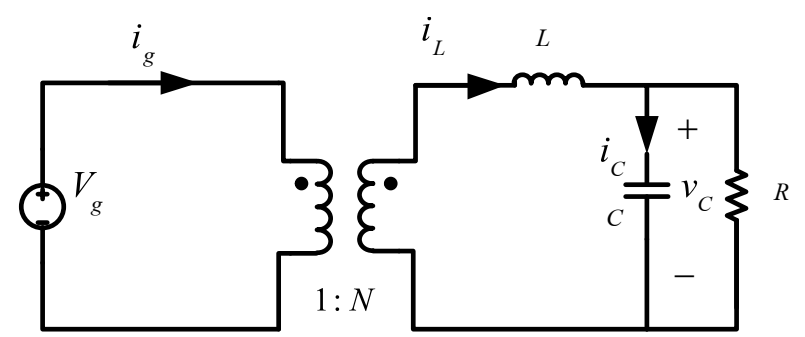

Fig. 2. The equivalent circuit of the proposed power converter 


\section{II.2. Small-Signal Model of a Full Bridge High-Power Converter}

Fig. 3 shows a small signal circuit for a full-bridge converter obtained with a PWM signal converter. The duty cycle is controlled by the values of the inductor voltage and the current [21]. The effective duty cycle can be expressed in (10):

$$
d_{e f f}=D_{e f f}+\hat{d}_{e f f}
$$

An effective cycle time depends not only on the duty cycle but also on the primary voltage, inductor filter, and the drop voltage of the leakage inductor. The effective duty cycle of the power converter is constant, and the small duty cycle changes due to the inductor current and the input voltage [22], which can be seen as given in (11):

$$
\hat{d}_{e f f}=\hat{d}+\hat{d}_{i}+\hat{d}_{v}
$$

$\hat{d}_{i}$ and $\hat{d}_{v}$ are the small change in the duty cycle due to the filter inductor current and the input voltage changing as shown in (12) and (13):

$$
\begin{gathered}
\hat{d}_{i}=\frac{4 n L_{r} f_{s}}{V_{i n}} \hat{i}_{L} \\
\hat{d}_{v}=\frac{4 n L_{r} f_{s}}{V_{i n}} \hat{V}_{i n}
\end{gathered}
$$

The transfer function from the equivalent circuit in Fig. 3 can be expressed as (14):

$$
\begin{aligned}
G(\mathrm{~s}) & =\frac{\hat{v}_{o}}{d}= \\
& =\frac{V_{\text {in }}}{L C} \frac{1}{s^{2}+s\left(\frac{L}{R}+R_{d} C\right)+\left(\frac{R_{d}}{R L C}+\frac{1}{L C}\right)}
\end{aligned}
$$

\section{II.3. Steady-State Analysis of Phase-Shifted Full-Bridge Power Converter}

Reducing the size and the weight of the magnetic components is desirable because it increases the switching frequency for high-frequency power converters. When conventional PWM converters operate at high frequencies, the circuit performance will be decreased.

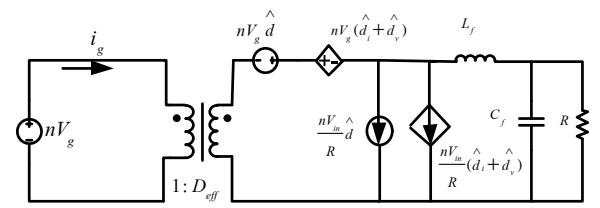

Fig. 3. The small-signal model of the proposed power converter
The increased power switching loss in high power applications should have insulation or other protection methods that reduce significant losses, which reduce efficiency. When operating a full-bridge power converter the shifting of phase control driving signal is used, there are two-step functions. The first step is to convert DC to $\mathrm{AC}$ by a full-bridge converter circuit connected with a high-frequency transformer. The second step is the AC to DC conversion by a high-frequency rectifier circuit with a low-pass filter.

The full-bridge power converter has four switches, similarly to the conventional full-bridge converter shown in Fig. 1.

The proposed control for switching $\mathrm{S}_{1}-\mathrm{S}_{4}$ is a phaseshifted PWM scheme that differs from the conventional control. The leg-pair switches are turned on complementarily with a $48 \%$ duty cycle, excluding the short dead time. The driving signals are shown in Fig. 4(b), where the second control signal has shifted the phase. The operation in the switching mode is zero, resulting in the current and in the voltage generated by the switch operation 1-4, as shown in Fig. 4(c). Fig. 5 shows the driving signals of $\mathrm{S}_{1}$ to $\mathrm{S}_{4}$, the primary voltage side of the transformer, $V_{p}$ and the secondary voltage side of the transformer $V_{s}$. The operation state can be explained by each mode as follows [23], [24].

- Mode 1: Loss of Duty Cycle: In mode $t=t_{0}$, the switches $S_{1}$ and $S_{4}$ are on; the switch $S_{1}$ is turned on with ZVS after ending mode $t_{0}$. The secondary voltage side of the transformer $V_{S}$ has remained zero until the current primary side of the transformer has been reversed to the positive direction and has increased to reach the reflected output inductor current $\left(I_{L_{f}}\right)$ in mode loss of duty cycle $t=t_{1}$;

- Mode 2: Power Transfer Mode: In mode $t=t_{1}$, the secondary voltage of the transformer is equal to $V_{i n}$, the $D_{1}-D_{4}$ rectifier diodes are forward biased and the energy is transferred from source to load. In the first operation mode of the phase-shifted $t_{1}-t_{2}$, the current across the output filters has begun to increase, and the primary current of the transformer $I_{p}$ has equalled the output inductor current that has reflected $\left(I_{L_{f}}\right)$;

- Mode 3: Zero voltage for the $S_{3}$ switch: In mode $t=t_{2}$, the $S_{4}$ switch is off, and the primary current of the transformer charges the $C_{4}$ of $S_{4}$ a switch and discharges the switch of $S_{3}$ when charging capacity $C_{3}$ is fully released. From $V_{\text {in }}$ to 0 , the diode $D_{3}$ will start to obtain zero voltage for the $S_{3}$ switch. This will reduce the damage to the switch. In this mode, the secondary voltages of the transformer turn into zero. The high-frequency rectifier diode $D_{1}$ and diode $D_{4}$ will conduct the electricity;

- Mode 4: Freewheel Through Switch Mode: In mode $t=t_{3}$, the $S_{3}$ switch with the ZVS and primary current of the high-frequency transformer $I_{P}$ is turned on and freewheeled through $S_{1}$ and $S_{3}$. The secondary voltage of the transformer $V_{S}$ is in the state of zero, and the load releases the output voltage; 


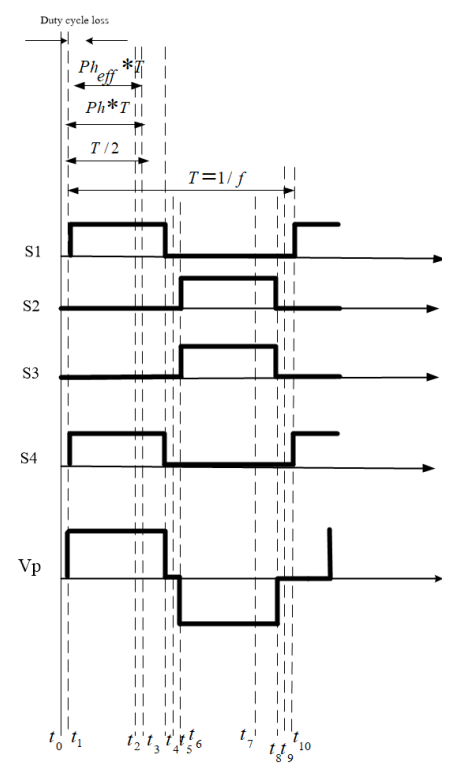

(a)

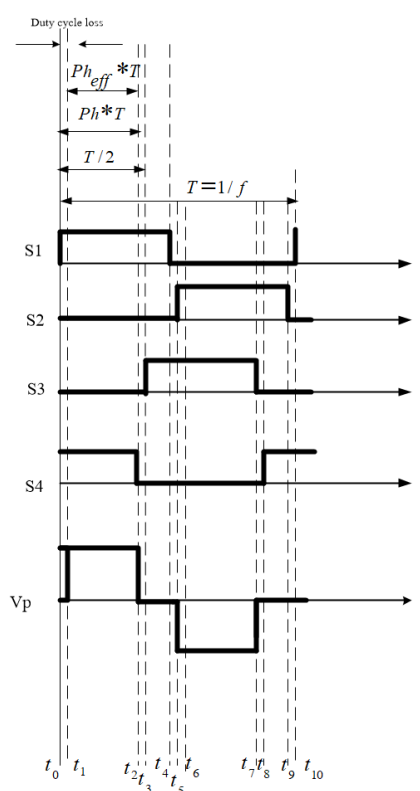

(b)

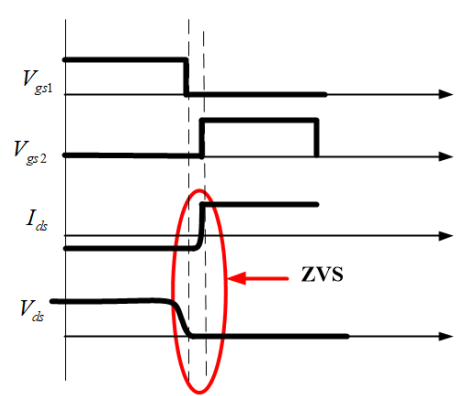

(c)

Figs. 4. (a) Conventional full-bridge PWM Converter (b) Principle of operation for the full-bridge phase-shifted power converter (c) The circuit for the ZVS mode of the power switch

- Mode 5: Zero Voltage for the $S_{2}$ Switch: In mode $t=t_{4}$, the switch $S_{1}$ is in the downstate, and the primary current of the transformer in the charging state $C_{1}$ connected with $S_{1}$ and then discharge $C_{2}$ is connected to the switch $S_{2}$. When the capacitance $C_{2}$ is completely released from $V_{\text {in }}$ to 0 , diode $D_{2}$ will be in zero voltage due to the switch for a switch $S_{2}$. The secondary voltage of the transformer remains zero voltage during the mode $t_{4}-t_{5}$;

- Mode 6: Loss of Duty Cycle: In mode $t=t_{5}$, the switch $S_{2}$ enables ZVS after the end of the mode $t_{4}$. The secondary voltage of the transformer $V_{S}$ is still at zero voltage until the primary current of the transformer $I_{P}$ reverses its direction and starts to increase the induction of the output current reflected in $I_{L_{f}}$ at period $t=t_{6}$. The primary current of the transformer increases according to the slope $V_{\text {in }} / L_{r}$, which ignores the induced leaking inductor $L_{r}$ and the lack of power transferred to the output;

- Mode 7: Power Transfer Mode: In mode $t=t_{6}$, the secondary voltage side of the transformer $V_{S}$ equals $V_{i n}$. The high-frequency rectifier diodes $D_{2}$ and $D_{3}$ are in the period in which the forward-biased diode and the transfer energy charge the inductor to pass power output. The first operation mode of the phaseshifted is in the working range of mode $t_{6}$. Crossinductor output currents begin to increase, and the primary current of the transformer $I_{P}$ flows in the negative direction equal to the electric current reflected in $I_{L_{f}}$;

- Mode 8: Zero Voltage for the $S_{2}$ Switch: In mode $t=t_{7}$, the switch is in the downstate, and the primary current of the high-frequency transformer will be in the charging state $C_{3}$ connected with $S_{3}$ and then discharge $C_{4}$, which is connected to the switch $S_{4}$. When the capacitance $C_{4}$ is completely released from $V_{\text {in }}$ to 0 , its device diode $D_{4}$ will be in the mode of zero voltage due to the switch $S_{4}$. In this mode, the secondary voltage of the high-frequency transformer becomes zero, and the high-frequency rectifier diode will carry the current;

- Mode 9: Freewheel Through Switch Mode: In mode $t=t_{8}$, the switch $S_{4}$ with the ZVS and primary current of the high-frequency transformer $I_{P}$ is turned on and it is freewheeled through $S_{2}$ and $S_{4}$. The secondary voltage of the high-frequency transformer $V_{S}$ is in the state of zero, and the output voltage is released by the load;

- Mode 10: Zero Voltage for the $S_{2}$ Switch: In mode $t=t_{9}$, the switch $S_{2}$ is in the downstate, and the primary current of the high-frequency transformer in the charging state $C_{2}$ is connected with $S_{2}$ and then it discharges $C_{1}$ that is connected to the switch $S_{1}$. When the capacitance $C_{1}$ is completely released from $V_{\text {in }}$ to 0 , its device diode $D_{1}$ will be in the mode of zero voltage due to the switch $S_{1}$ solving problems of loss in switch devices. In this part, the secondary voltage of the high-frequency transformer returns to zero, and in the rectifier circuit $D_{2}$, and $D_{3}$ are in current condition [25]. 

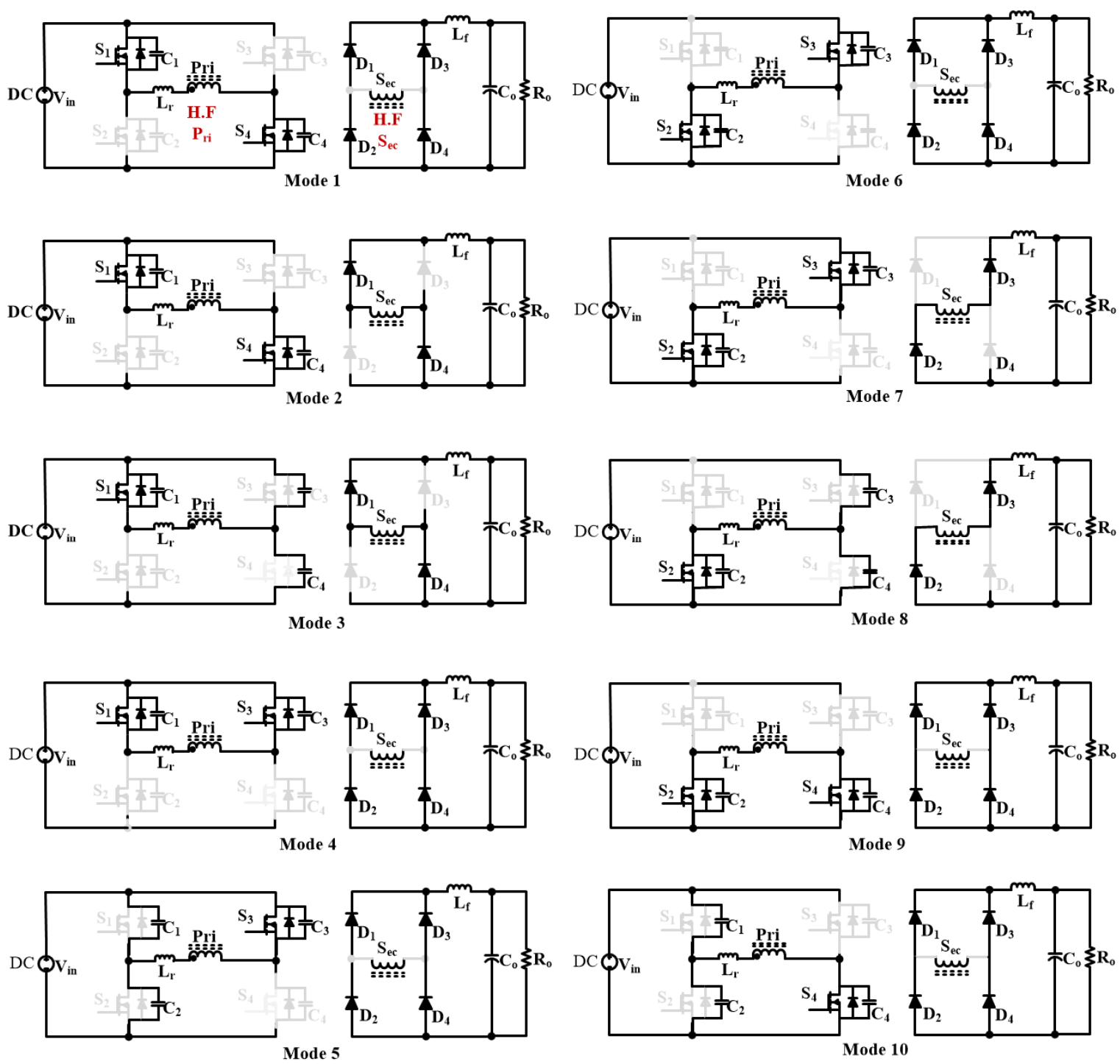

Fig. 5. The equivalent circuit of the operating mode of the phase-shifted full-bridge power converter

\section{Model of High-Frequency Transformer}

The high-frequency transformers are designed to support integration with power electronic switches in the form of high-frequency signals.

They are designed to obtain the output voltage maintained among the lowest input voltage when the maximum load is connected. The duty cycle is an important parameter in controlling the system's operation to transfer the energy of the transformer from the primary side to the secondary side.

The offset time of each working period is halfworking alternately to reverse the system's primary side and allow the current to flow to the current circuit on the secondary side of the high-frequency transformer. As a result, the loss of work cycles is considered when calculating the rotation ratio. Otherwise, the converter may have a high loss value [26], [27] during the control period under extreme load conditions, especially if it exists. For higher leakage induction values [28], the voltage is shown in (15):

$$
\frac{V_{o}}{V_{\text {in }}}=\frac{N_{s}}{N_{p}} p h_{\text {eff }}-I_{o}\left(\frac{N_{s}}{N_{p}}\right) \frac{L_{r}}{V_{i n}} f
$$

The energy loss from the transformer ratio, without the cupper loss, can be calculated by (16):

$$
p h_{e f f}=\frac{V_{o}}{V_{\text {in }}} \frac{N_{p}}{N_{s}}
$$

The principle of choosing the size and the shape of the transformer will mainly consider the efficiency and the increasing temperature. Some transformer design experiences, along with a few repetitions, need to choose the most appropriate axis with a balanced core and loss of coil.

The loss of an acceptable axis will determine the maximum magnetic flux limit at 0.1 Tesla. Therefore, the number of primary windings of the transformer can be calculated as shown in (17): 


$$
\begin{aligned}
& N_{p}=\frac{V_{\text {in }} p h_{\text {eff }}}{2 B_{\text {max }} A_{c} f} \\
& B_{\max }=\frac{V_{\text {in }} p h_{\text {eff }}}{2 N_{p} A_{c} f}
\end{aligned}
$$

The ripple of the inductor current can be calculated from (19):

$$
\Delta I_{L_{f}}=\% \text { Ripple } \frac{I_{o}}{2}
$$

The inductance of the $L_{f}$ filter and the maximum current are determined according to the induced ripple current as shown in (20):

$$
L_{f}=\frac{1}{\Delta I_{L_{f}}} V_{o}\left(1-p h_{e f f}\right) T
$$

The output of the capacitor ripple current is a function other than the phase-shifted of power conversion circuit.

The current rectifier can completely reduce the current ripple incapacity in the case of $p h_{\text {eff }}=0.48$. The current ripple output capacitor, the rms current, and the ESR loss can be calculated from (21) to (23):

$$
\begin{gathered}
\Delta I_{C o}=\frac{V_{o}}{L_{f}} T\left(1-2 p h_{\text {eff }}\right) \\
I_{\text {Corms }}=\sqrt{\frac{1}{12} \Delta I_{C o}} \\
P_{\text {Co }}=I_{\text {Corms }^{2}} E S R_{\text {out }}
\end{gathered}
$$

The ripple voltage of the capacitor value can be calculated from (24):

$$
\Delta V_{C o}=\frac{V_{o}\left(1-2 \times p h_{e f f}\right) T^{2}}{16 L_{f} C_{o}}
$$

The capacitor value used to filter the output voltage can be calculated as shown (25):

$$
C_{o}=\frac{V_{o}\left(1-2 p h_{e f f}\right) T^{2}}{16 L_{f} \Delta V_{C o}}
$$

\section{Design of Proposed High-Frequency Power Converter}

This section focuses on the design of phase-shifted full-bridge power converters for photovoltaic systems.

The system component in the first part is the full- bridge phase-shifted power converter with ZVS softswitching operation. This power converter is directly connected to the primary side of the high-frequency transformer, and the secondary side of the highfrequency transformer is also connected to the highfrequency power rectifier circuit. The specific parameters of the proposed power converter have been designed as shown in Table I. In the case of reducing the losses caused by transformer isolation, the ferrite core with low saturation flux density is considered the magnetic core with the highest magnetic flux range $B_{\max }$ of $0.2 T$. The area size for the core $A_{C}$ of $1.5 \mathrm{~cm}^{2}$ determines the number of coils around the primary side of the highfrequency transformer, as shown in (26):

$$
N_{p}=\frac{V_{\text {in }} D}{2 B_{\max } A_{c} f} \times 10^{8}
$$

Determining the number of primary windings of the high-frequency transformer six turns meets the output voltage requirements and supports the voltage across the circuit element. The secondary voltage of the highfrequency transformer should be calculated based on the ratio of the output voltage with the maximum duty cycle value as shown in (27):

$$
V_{\mathrm{sec}} \geq \frac{V_{o}}{D_{\max }}
$$

The duty cycle value is defined as $48 \%$, and the secondary voltage of the high-frequency transformer equation is $V_{o}=D_{\text {eff }} \times V_{\text {sec }}$.

The number of the secondary windings of the highfrequency transformer can be calculated from the equation shown in (28):

$$
N_{s}=N_{p} \frac{V_{\mathrm{sec}}}{V_{\text {in }}}
$$

The inductor value used to filter the output voltage of the power converter is determined by the efficiency input voltage and the output voltage, and the duty cycle performance value is given by (29) [29]:

$$
L_{f}=\frac{\left(\eta V_{i n}-V_{o}\right) D_{e f f}}{\Delta I_{L} f_{s}}
$$

The ripple current, $\Delta I_{L}$, for the inductor has been set at $10 \%$, and the inductor used for filtering voltage has been $0.95 \mathrm{mH}$.

The output filter capacitor has been determined by selecting the ripple voltage output $\Delta V_{o}=0.25 \%$, as shown in (30):

$$
\Delta V_{c}=\frac{V_{o}\left(1-D_{e f f}\right)}{16 f_{s}^{2} C L_{f} f_{s}}
$$


TABLE I

PARAMETERS OF THE DESIGNED POWER CONVERTER

\begin{tabular}{cc}
\hline \hline Items & Value \\
\hline Input voltage $V_{\text {in }}$ & $400 \mathrm{VDC}$ \\
PV output voltage range & 370 VDC - 400 VDC \\
Battery voltage $V_{\text {out }}$ & $24 \mathrm{VDC}$ \\
Output voltage ripple $\Delta V_{\text {out }}$ & $0.25 \%$ \\
Switching frequency $f_{s}$ & $50 \mathrm{kHz}$ \\
Maximum duty cycle $D_{\max }$ & $50 \%$ \\
\hline \hline
\end{tabular}

The resonant frequency of the ZVS switching between the energy stored in the transformer leakage inductors and the capacitor of the MOSFET power switching devices for the four switches is calculated as shown in Eq. (31) [30]-[32]:

$$
f_{r}=\frac{1}{2 \pi \sqrt{L_{r} C_{r}}}
$$

The leakage inductance is calculated as shown in (32):

$$
L_{r}=4 t_{d}^{2} / \pi^{2} C_{r}
$$

\section{Simulation Results}

The full-bridge high-frequency power converter for photovoltaic application tested the operation and the performance of the proposed system. The MATLAB/Simulink environment has been selected for simulating the whole function. In the first part of the power circuit, the full-bridge phase-shifted ZVS power converter has operated under PWM switching signals.

The shifting method of driving phase signal has allowed the switching scheme of the power device to be in ZVS mode and has resulted in effective voltage control. The second part has been a high-frequency power rectifier circuit that has converted AC-DC voltage with a high-frequency diode device, $D_{1}-D_{4}$, as presented in Fig. 1. Fig. 6 shows the prototype of a full-bridge high-frequency power converter used to test the whole performance function. The PWM switching signals, $S_{1}$ $\mathrm{S}_{4}$, with the phase-shifted method, have showed a simplified circuit of a phase-shifted full bridge power converter. The duty cycle of the switch signal has been $50 \%$. The driving signal of the power switch of $S_{1}$ and $S_{2}$ has been divided into $50 \%$ of the switching period. Similarly, $S_{3}$ and $S_{4}$, the performance of the phase-shifted signal is shown in Fig. 7. Fig. 8 shows the switching operation in the phase-shifted full-bridge power converter circuit on the primary side of the highfrequency transformer, where the relationship between $V_{G S}$ and $V_{D S}$ shows that $S_{1}-\mathrm{S}_{4}$ have achieved ZVS function in different output power levels.

The simulation results have showed the primary voltage and the primary current of the high-frequency transformer obtained from the full-bridge phase-shifted power converter circuit. The PWM waveforms powered by the phase-shifted method of $S_{1}-\mathrm{S}_{4}$ switches according to the conditions described above are presented in Fig. 9.

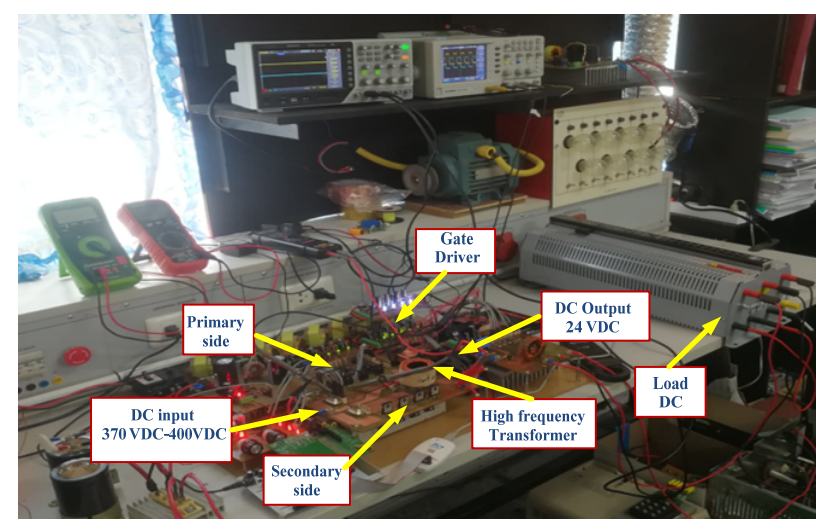

Fig. 6. Prototype of the full-bridge high-frequency power converter
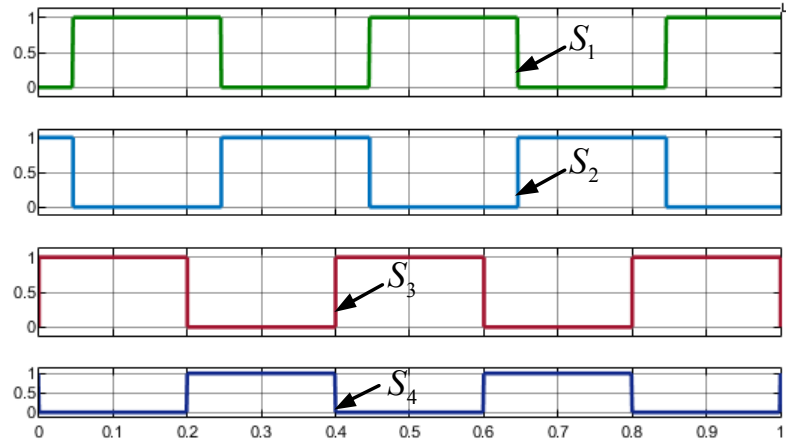

Fig. 7. Driving Signal, $\mathrm{S}_{1}-\mathrm{S}_{4}$, of the proposed power converter

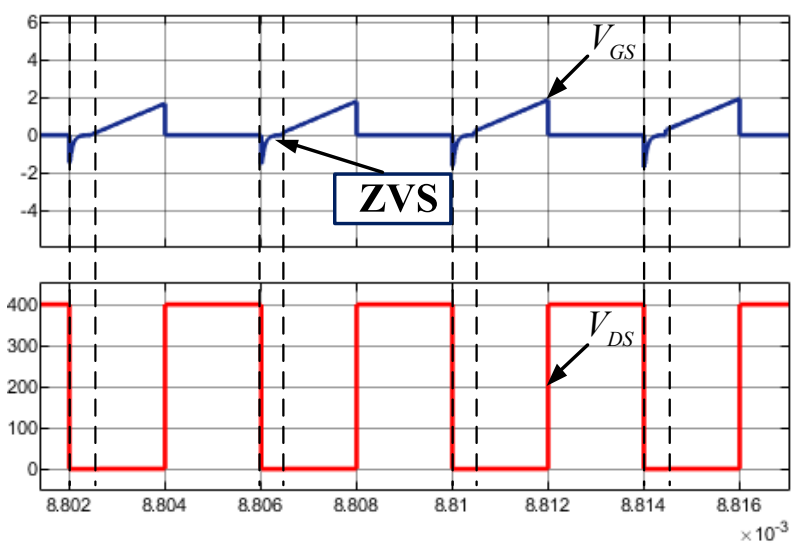

Fig. 8. The waveforms for the ZVS mode of the power switch

The simulation results have showed that the highfrequency transformer's secondary voltage and the secondary current had the output voltage control, as shown in Fig. 10. Fig. 11 shows that changing input voltage by switching the full-bridge phase-shifted power converter, which has maintained the rated voltage of 370 VDC-400 VDC, and the circuit phase-shifted full-bridge power output voltage converter has been able to be controlled at a constant of 24 VDC. The output voltage regulation of the proposed power converter has been obtained by generating electricity with renewable energy, especially the photovoltaic application. The proposed phase-shifted full-bridge power converter can achieve the required design rating compared to the conventional power converter circuits from the simulation results. 

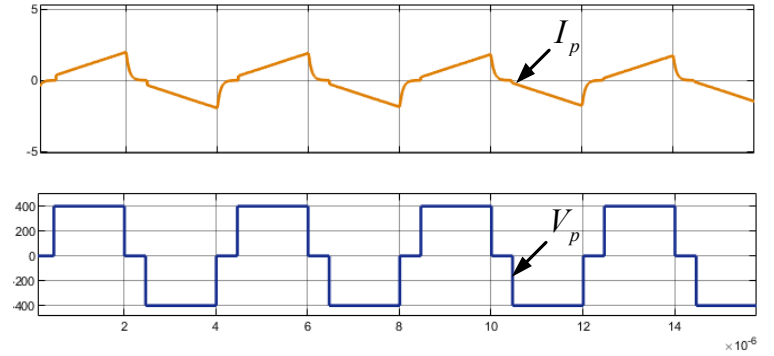

Fig. 9. Primary voltage and current of the full-bridge phase-shifted power converter
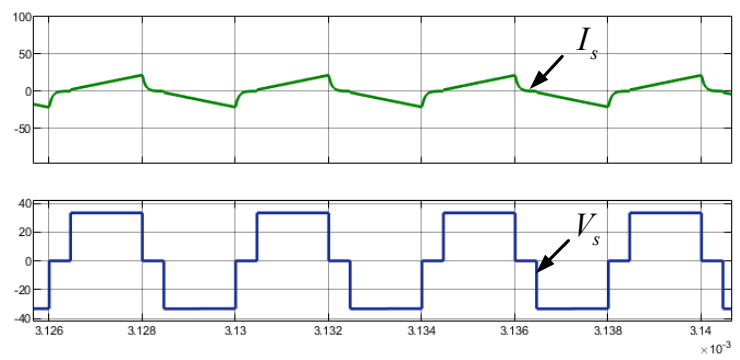

Fig. 10. Secondary voltage and current of the full-bridge phase-shifted power converter
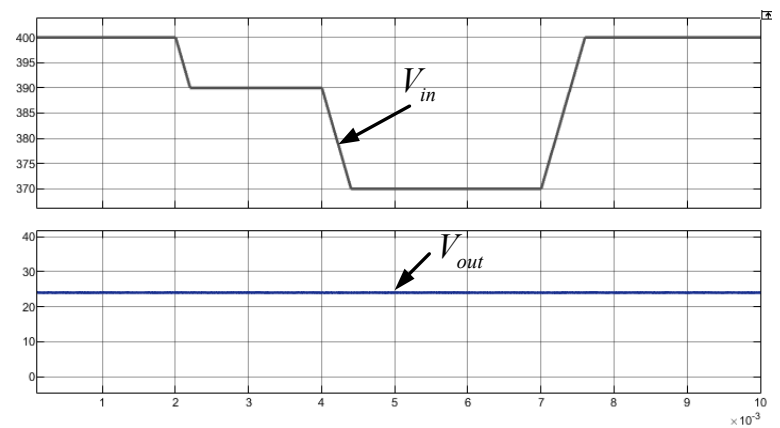

Fig. 11. Comparison between the input voltage and output voltage of power converter when changing the state of the switching

The phase-shifted full-bridge power converter takes advantage of the switch operating range element in the power circuit in order to ensure zero voltage switching by providing a ZVS soft switch scheme. The simulated power converter has selected the phase-shifted principle in conjunction with a high-frequency transformer. It has controlled the output voltage of the power converter circuit to the desired constant values.

New switching control techniques for full-bridge converters are presented under controlled conditions in phase-shifted switching mode in a zero-voltage switching.

The simulation results of loss analysis patterns and pivot points between a mode for full-bridge converters are presented with an input voltage range of $370 \mathrm{VDC}$ to $400 \mathrm{VDC}$ and controlled output voltage at $24 \mathrm{VDC}$. The phase-shifted ZVS of full-bridge power converter has been operated under the zero-voltage switch principle and the control signal PWM in the phase-shifted technique.

The power converter has consisted of a high- frequency full-bridge power converter circuit to increase the DC voltage level at the rated voltage of $400 \mathrm{VDC}$ to 24 VDC.

The simulation results have showed that when the input voltage has changed the full-bridge phase-shifted ZVS power converter at the rated voltage of $370 \mathrm{VDC}-$ $400 \mathrm{VDC}$, the output voltage of the full-bridge phaseshifted ZVS power converter could control the output voltage at a constant of 24 VDC.

\section{Conclusion}

This paper has proposed the phase-shifted full-bridge power converter, which has operated under the ZVS principle together with the phase-shifted technique of PWM driving signal of power switches. The proposed high-frequency power converter operates using the fullbridge power converter circuit in order to control the desired voltage level at the rated voltage. The highfrequency transformer is designed under the optimal sizing with small size and low switching loss criterion.

The power rectifier circuit and the low pass filter are also designed under the optimal condition and the desired value.

The simulation results have showed that the proposed phase-shifted full-bridge power converter could control the varying input voltage from the photovoltaic source to the rated desired voltage. The output voltage of the phase-shifted full-bridge power converter has been controlled at a constant of 24 VDC for battery charging applications.

By controlling the proposed switch, the technique can significantly reduce losses under standby and light load conditions and provide satisfactory dynamic performance even under changing between different modes.

Therefore, there is a considerable possibility that the proposed techniques can be the parliamentary design of a phase-shifted power converter for future works.

\section{References}

[1] T. Suntio, T. Messo, A. Aapro, J. Kivimäki, K. Kuperman, Review of PV Generator as an Input Source for Power Electronic Converters, Energies, vol. 10 n. 8, July 2017, pp. 1076-1100. doi: https://doi.org/10.3390/en10081076

[2] A. Del Pizzo, L.P. Di Noia, S. Meo, Super Twisting Sliding mode control of Smart-Inverters grid-connected for PV applications, 6th International Conference on Renewable Energy Research and Applications (ICRERA), November 5-8, 2017, San Diego, CA, USA.

doi: https://doi.org/10.1109/icrera.2017.8191168

[3] S. Meo, L. Toscano, Some new results on the averaging theory approach for the analysis of power electronic converters, IEEE Transactions on Industrial Electronics, vol. 65, December 2018, pp. 9367-9377. doi: https://doi.org/10.1109/TIE.2018.2821620

[4] Di Noia, L., Del Pizzo, A., Meo, S., Reduced-Order Averaged Model and Non-Linear Control of a Dual Active Bridge DC-DC Converter for Aerospace Applications, (2017) International Review of Aerospace Engineering (IREASE), 10 (5), pp. 259-266. doi: https://doi.org/10.15866/irease.v10i5.13818

[5] G. Brando, A. Del Pizzo, S. Meo, Model-Reference Adaptive Control of a Dual Active Bridge DC-DC Converter for Aircraft 
Applications, International Symposium on Power Electronics, Electrical Drives, Automation and Motion (SPEEDAM), June 2022, 2018, Amalfi, Italy. doi: https://doi.org/10.1109/SPEEDAM.2018.8445242

[6] S. Meo, L. Toscano, On the existence and uniqueness of the ode solution and its approximation using the means averaging approach for the class of power electronic converters, Mathematics, vol. 9 n. 10, May 2021, pp. 1146-1157. doi: https://doi.org/10.3390/math9101146

[7] A. Cervone, G. Brando, O. Dordevic, A.D. Pizzo, S. Meo, An adaptive multistep balancing modulation technique for multipointclamped converters, IEEE Transactions on Industry Applications, vol.56, October 2019, pp. 465-476. https://doi.org/10.1109/TIA.2019.2949980

[8] Compala Lakshmiah, K., Raghavendiran, T., A New Modified HBridge Multilevel Inverter with Multi Carrier PWM Technique for Speed Control of Induction Motor, (2018) International Review of Electrical Engineering (IREE), 13 (5), pp. 365-372. doi: https://doi.org/10.15866/iree.v13i5.15501

[9] Pirino, P., Losito, M., Kumar, A., Gatto, G., Meo, S., Frank, W., Moradpour, M., Multi-Objective Gate Driver Design for a GaNBased Half-Bridge Converter to Optimize Efficiency and NearField EMI, (2021) International Review of Electrical Engineering (IREE), 16 (2), pp. 95-103.

doi: https://doi.org/10.15866/iree.v16i2.20477

[10] J. Viinamäki, A. Kuperman, T.Suntio, Grid-Forming-Mode Operation of Boost-Power-Stage Converter in PV-GeneratorInterfacing Applications, Energies, vol.10 n.7, July 2017, pp. 1033-1055.

doi: https://doi.org/10.3390/en10071033

[11] S.K. Mazumder, R. Burra, R. Huang, M. Tahir, K. Acharya, G. Garcia, S. Pro, O. Rodrigues, E. Duheric, A universal gridconnected fuel-cell inverter for residential application, IEEE Transactions on Industrial Electronics, vol.57, January 2010, pp. 3431-3447. doi: https://doi.org/10.1109/TIE.2009.2038943

[12] P. Madasamy, V. Suresh Kumar, P. Sanjeevikumar, J.B. HolmNielsen, E. Hosain, C. Bharatiraja, A Three-Phase Transformerless T-Type- NPC-MLI for Grid-Connected PV Systems with Common-Mode Leakage Current Mitigation, Energies, vol.12 n.12, June 2019, pp. 2434-2458. doi: https://doi.org/10.3390/en12122434

[13] M.T. Sarniak, J. Wernik, K.J. Wołosz, Application of the Double Diode Model of Photovoltaic Cells for Simulation Studies on the Impact of Partial Shading of Silicon Photovoltaic Modules on the Waveforms of Their Current-Voltage Characteristic. Energies, vol.12 n.12, June 2019, pp. 2421-2430. doi: https://doi.org/10.3390/en12122421

[14] Z. Wang, Y. Li, Z. Li, C. Zhao, F. Gao, and P. Wang, ReducedOrder DC Terminal Dynamic Model for Multi-Port AC-DC Power Electronic Transformer, Energies, vol.12 n.11, June 2019, pp. 2130-2145. doi: https://doi.org/10.3390/en12112130

[15] M.D. Vecchia, G.V. Broeck, S. Ravyts, J. Driesen, Novel StepDown DC-DC Converters Based on the Inductor-Diode and Inductor-Capacitor-Diode Structures in a Two-Stage Buck Converter, Energies, vol.12 n.6, March 2019, pp. 1131-1152. doi: https://doi.org/10.3390/en12061131

[16] R.H. Ashique, Z. Salam, A Family of True Zero Voltage Zero Current Switching (ZVZCS) Nonisolated Bidirectional DC-DC Converter With Wide Soft Switching Range, IEEE Transactions on Industrial Electronics, vol.64 n.7, July 2017, pp. 5416-5427. doi: https://doi.org/10.1109/TIE.2017.2669884

[17] C.M. Lai, M.J Yang, S.K. Liang, A Zero Input Current Ripple ZVS/ZCS Boost Converter with Boundary-Mode Control, Energies, vol.7 n.10, October 2014, pp.6765-6782. doi: https://doi.org/10.3390/en7106765

[18] L. Zhao, H. Li, Y. Yu, Y. Wang, A Novel Choice Procedure of Magnetic Component Values for Phase Shifted Full Bridge Converters with a Variable Dead-Time Control Method, Energies, vol.8 n.9, September 2015, pp. 9655-9669 doi: https://doi.org/10.3390/en8099655

[19] Y. Shi, X. Gui, J. Xi, X. Wang, X. Yang, Large Power Hybrid Soft Switching Mode PWM Full-Bridge DC-DC Converter With
Minimized Turn-on and Turn-off Switching Loss, IEEE Transactions on Power Electronics, vol.34 n.12, March 2019, pp. 11629-11644. doi: https://doi.org/10.1109/TPEL.2019.2904982

[20] F. Jauch and J. Biela, Combined Phase-Shift and Frequency Modulation of a Dual-Active-Bridge AC-DC Converter With PFC, IEEE Transactions on Power Electronics, vol.31, December 2016, pp. 8387-8397. doi: https://doi.org/10.1109/TPEL.2016.2515850

[21] B. Zhang, S. Xie, X. Wang and J. Xu, Modulation Method and Control Strategy for Full-Bridge-Based Swiss Rectifier to Achieve ZVS Operation and Suppress Low-Order Harmonics of Injected Current, IEEE Transactions on Power Electronics, vol. 35 , no. 6 , June 2020, pp. 6512-6522. doi: https://doi.org/10.1109/TPEL.2019.2951795

[22] D. Tran, N. Vu, C. Choi, A Quasi-Resonant ZVZCS PhaseShifted Full-Bridge Converter with an Active Clamp in the Secondary Side, Energies, vol. 11, no. 11, October 2018, pp. 2868-2888.

doi: https://doi.org/10.3390/en11112868

[23] K. Shi, D. Zhang, Z. Zhou, M. Zhang, D. Zhang Y. Gu, A Novel Phase-Shift Dual Full-Bridge Converter With Full Soft-Switching Range and Wide Conversion Range, IEEE Transactions on Power Electronics, vol. 31, no. 11, November 2016, pp. 7747-7760. doi: https://doi.org/10.1109/TPEL.2015.2512848

[24] A. Safaee, P. Jain, A. Bakhshai, A ZVS Pulsewidth Modulation Full-Bridge Converter With a Low-RMS-Current Resonant Auxiliary Circuit, IEEE Transactions on Power Electronics, vol. 31, no. 6, June 2016, pp. 4031-4047. doi: https://doi.org/10.1109/TPEL.2015.2473822

[25] M. Escudero, D. Meneses, N. Rodriguez D.P. Morales, Modulation Scheme for the Bidirectional Operation of the PhaseShift Full-Bridge Power Converter, IEEE Transactions on Power Electronics, vol. 35, no. 2, February 2020, pp. 1377-1391. doi: https://doi.org/10.1109/TPEL.2019.2923804

[26] G. Li, J. Xia, K. Wang, Y. Deng, X. He, Y. Wang, Hybrid Modulation of Parallel-Series LLC Resonant Converter and Phase Shift Full-Bridge Converter for a Dual-Output DC-DC Converter, IEEE Journal of Emerging and Selected Topics in Power Electronics, vol. 7, no. 2, June 2019, pp. 833-842. doi: https://doi.org/10.1109/JESTPE.2019.2900700

[27] T. Liu, X. Yang, W. Chen, Y, Li, Y, Xuan, L. Huang, X, Hao, Design and Implementation of High-Efficiency Control Scheme of Dual Active Bridge Based $10 \mathrm{kV} / 1$ MW Solid State Transformer for PV Application, IEEE Transactions on Power Electronics, vol. 34, no. 5, May 2019, pp. 4223-4238. doi: https://doi.org/10.1109/TPEL.2018.2864657

[28] G.Bon. Koo, G.W. Moon, M.J. Youn, Analysis and design of phase-shift full-bridge converter with series-connected two transformers, IEEE Transactions on Power Electronics, vol. 19, no. 2, March 2004. pp. 411-419. doi: https://doi.org/10.1109/TPEL.2003.823193

[29] J. Zhang, J. Liu, J. Yang, N. Zhao, Y. Wang, T.Q. Zheng, A Modified DC Power Electronic Transformer Based on Series Connection of Full-Bridge Converters, IEEE Transactions on Power Electronics, vol. 34, no. 3, March 2019, pp. 2119-2133. doi: https://doi.org/10.1109/TPEL.2018.2842728

[30] J. Wu, Y. Li, X. Sun, F. Liu, A New Dual-Bridge Series Resonant DC-DC Converter With Dual Tank, IEEE Transactions on Power Electronics, vol. 33, no. 5, May 2018, pp. 3884-3897. doi: https://doi.org/10.1109/TPEL.2017.2723640

[31] Z. Guo, D. Sha, Dual-Active-Bridge Converter With parallelconnected Full Bridges in Low-Voltage Side for ZVS by Using Auxiliary Coupling Inductor, IEEE Transactions on Industrial Electronics, vol. 66, no. 9, September 2019, pp. 6856-6866. doi: https://doi.org/10.1109/TIE.2018.2877145

[32] H. Moradisizkoohi, N. Elsayad, O. A. Mohammed, Experimental Demonstration of a Modular, Quasi-Resonant Bidirectional DCDC Converter Using GaN Switches for Electric Vehicles, IEEE Transactions on Industry Applications, vol. 55, no. 6, Nov.-Dec. 2019, pp. 7787-7803.

doi: https://doi.org/10.1109/TIA.2019.2914648 


\section{Authors' information}

${ }^{1}$ Electrical Engineering Department, Engineering School, RMUTT, Thanyaburi, Thailand.

${ }^{2}$ Electrical Engineering Department, The Rajamangala University of Technology Isan, Thailand.

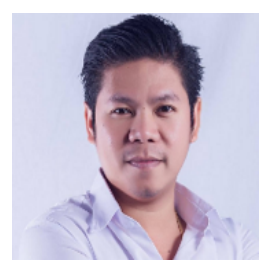

Wasan Phetphimoon received his B.Eng. degree in electrical engineering from Rajamangala University of Technology Lanna (RMUTL), Tak, Thailand in 2007, and M.Eng. in electrical engineering from Rajamangala University of Technology Thanyaburi (RMUTT), Pathum Thani, Thailand, in 2010. He is currently a doctoral student of Electrical Engineering, Department of Electrical Engineering, Faculty of Engineering, Rajamangala University of Technology Thanyaburi (RMUTT), Thailand. He works at the Department of Electrical Engineering Technology, Faculty of Industrial Technology, Kamphaeng Phet Rajabhat University (KPRU), Thailand. His research interests are in power electronics applications in renewable energy.

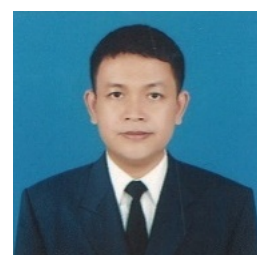

Yuttana Kongjeen received his B. Eng degree and M. Eng degree in engineering from Rajamangala University of Technology Isan (RMUTi), Nakhonratchasima, Thailand in 2000 and 2005 , respectively. He also obtained a D.Eng. degree in electrical engineering from Rajamangala University of Technology Thanyaburi (RMUTT), Pathum Thani, Thailand, in 2018. His research interests lie in power system optimization techniques, energy storage systems, power system stability, and renewable energy integration system.

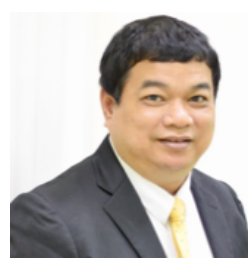

Krischonme Bhumkittipich (Corresponding Author) received his B.Eng. degree in electrical power engineering from Rajamangala University of Technology Thanyaburi (RMUTT), Pathum Thani, Thailand in 1997, an M.Eng. degree in electrical engineering from Chulalongkorn University, Bangkok, Thailand in 2000, and a D.Eng. degree in energy from Asian Institute of Technology, Pathum Thani, Thailand, in 2008. From 2002-2004, he worked as a research associate at the Institute of Power Electronics and Electrical Drives (ISEA), RWTH-Aachen University, Aachen, NRW, Germany. He is currently an Associate Professor with the Department of Electrical Engineering, Faculty of Engineering, RMUTT. He is also the Vice President of Academic and Research Affairs at RMUTT, Pathum Thani, Thailand. He is a senior member of IEEE, an active member of IEEE Power \& Energy Society, IEEE Power Electronics Society, IEEE Industry Applications Society, IEEE Dielectrics and Electrical Insulation Society, and a member of the Institute of Electrical Engineering of Japan (IEEJ). He is on the board committee of the IEEE Power and Energy Society-Thailand chapter. His research interests are in future electric power grids, power system dynamics and stability, power system interconnection, electric vehicle, smart mobility, analytical studies on the complexity of power systems, and future innovation for smart social life in a smart city. 